Www.jmscr.igmpublication.org

Impact Factor (SJIF): 6.379

Index Copernicus Value: 79.54

ISSN (e)-2347-176x ISSN (p) 2455-0450

crossrefDOI: https://dx.doi.org/10.18535/jmscr/v6i9.43

Journal Of Medical Science And Clinical Research

IGM Publication

An Official Publication of IGM Publication

\title{
Study of Traditional Cultural Practices and Beliefs on Neonatal Care among Mothers - A tertiary care hospital based study
}

\author{
Authors \\ Arakhita Swain ${ }^{*}$, Kaushik Mishra', Dipankar Mandal ${ }^{3}$, Saiprasanna Behera ${ }^{4}$, \\ Saroj Kumar Satpathy ${ }^{5}$ \\ ${ }^{1}$ Professor, Department of Paediatrics, SLN Medical College and Hospital, Koraput, (Formerly, Associate \\ Professor of Paediatrics, SCB MC, Cuttack), Odisha \\ ${ }^{2}$ Professor, Department of Community Medicine, SLN Medical College and Hospital, Koraput, (Formerly, \\ Associate Professor of Community Medicine, SCB MC, Cuttack), Odisha \\ ${ }^{3}$ FNB, Paediatric Nephrology, Mehta Children Hospital, Chennai \\ ${ }^{4}$ Research Associate in Paediatrics, SCB Medical College and SVP PGIP, Cuttack, Odisha \\ ${ }^{5}$ Professor, HOD of Paediatrics, SCB Medical College, Cuttack, Odisha \\ *Corresponding Author \\ Dr Arakhita Swain \\ Professor, Department of Paediatrics, SLN Medical College and Hospital, Koraput, Odisha, India \\ Email: aaswain@yahoo.com, Tel. No.9437037373
}

\begin{abstract}
Background: The Indian society is still tradition bound to a large extent, majority traditional and cultural practices being follow during neonatal age, the period, contributing to the maximum risk of mortality and morbidity. The influence is relatively more in remote rural areas, difficult terrains of tribal regions and poverty ridden urban slums particularly, under the influence of elderly ladies of the family and neighbourhood. In India, mothers are not equipped with sufficient knowledge about child care and using traditional child care methods which might cause harm to their children's health and even cause handicaps in their children. Paucity of literature on Traditional / Cultural Beliefs and Practices prompted to go for the present study for probing into the issues and establishing any factual relationship, if at all exists.

Materials and Methods: It is a tertiary care Hospital based descriptive (KAP) study where all the newborn babies admitted to the department of Pediatrics at SVP PGIP \& SCBMCH, CUTTACK, or those came to OPD at SVPPGIP, CTC, were considered for the study during a period of 2 years from 1 st August 2014 to 31st July 2016. Critically ill neonates were excluded from the study. A structured dichotomous questionnaire was prepared, validated and followed for data collection, analysis and compilation.

Results: Out of 170 mothers, majority (64.1\%) were in the age group of 25 years or below, $61.8 \%$ belonged to Joint family or extended family, 91.2\% of mothers belonged to Hindu religion, most (>80\%) were underMatric, more than $40 \%$ (40.6\%) mothers had family income less than Rs. 9794. Old cloth was used for wrapping of majority of babies (69.4\%) after birth,11 babies were wrapped after 30 minutes of delivery. 95.9\% mothers massaged the baby with oil before bath and 92.4\% mothers bathed baby after 1 week of life. $54 \%$ mothers initiated breast feeding within 1 hour while, $24.7 \%$ initiated within 1 to 4 hours and $15.9 \%$ mothers started after 24 hours. $91.8 \%$ mothers gave colostrums to their babies. $75.9 \%$ mothers buried the
\end{abstract}


cord once it was fallen while $12.4 \%$ mothers threw the cord into pond after falling. Applying Kajal on face and forehead practiced in $98.2 \%$ of babies.

Conclusion: Some of the practices performed by the mothers are very good and must be encouraged, some are very much harmful and need to be discouraged while some are harmless having no negative effect on the babies which should be simply ignored. Cultural practices and beliefs should be taken into account and consideration while planning for different National Health Programmes exclusively targeted at and promoted towards the improvement of the health status of Mothers and Babies.

Keywords: Traditional Cultural Practices, Neonatal Care.

\section{Introduction}

Essential new born care practices during delivery and neonatal period contribute to risk of mortality and morbidity. The Indian society is still tradition bound to a large extent almost all the families having their own traditions of neonatal care. In fact, maximum traditional and cultural practices are followed during neonatal period in $\operatorname{India}^{[1]}$.

A large number of newborns are home delivered and do not have an easy access to modern medical services and reared largely through traditional and cultural practices. The influence is relatively more in remote rural areas, difficult terrains of tribal regions and poverty ridden urban slums. Under the influence of elderly ladies of the family and neighbourhood, even the educated and urban elite are also to a certain extent are not exempted from some untoward traditional cultural neonatal care practices $^{[2]}$. Studies show evidence about contribution of care practices immediately following delivery to neonatal mortality and morbidity. Most newborns in low income country like India die at home while they are cared by mothers, relatives and traditional birth attendant ${ }^{[3]}$. In India, mothers are not equipped with sufficient knowledge about child care and using traditional child care methods which might cause harm to their children's health and even cause handicaps in their children ${ }^{[4]}$.

In our community women receive information from family members, elders and traditional birth attendants. Hence these groups, expectant mothers of newborns should be targeted with educational messages. Hence exploration of cultural beliefs and practices of newborn care is essential ${ }^{[5]}$. There is paucity of literature on Traditional / Cultural Beliefs and Practices, Nationally, in general and in this part of Odisha state in particular. Hence, this present study "Traditional Cultural Practices and Beliefs on neonatal care among mothers" has been designed for probing into the issues and establishing any factual relationship, if at all exists.

\section{Aims and Objectives}

The present study has been conducted with an aim to 1) know the prevalence of traditional cultural practices and beliefs that exist among the mothers in Odisha, 2) find out the association between cultural practices and beliefs related to child bearing and selected demographic variables and 3) determine the distribution of harmless, harmful and welcoming practices prevailing in relation to the traditional newborn care practices in Odisha and an objective of attempting at the probable solutions depending upon the type of the practices prevailed and providing healthy babies to the parents and the society.

\section{Materials and Methods}

All the newborn babies admitted to the department of Pediatrics at SVP PGIP \& SCBMCH, CUTTACK, or those came to OPD at SVPPGIP, CTC, were considered for the study. Study Design: Tertiary care Hospital based descriptive (KAP) study. Study Period: 2 years from 1st August 2014 to 31st July 2016. Sample Size: All neonates admitted at SVPPGIP \& SCBMCH during the study period and all the Newborns that come to OPD. Inclusion Criteria: All Neonates (<28 days of age) were included. Exclusion Criteria:1. Babies $>28$ days of life.2. Critically ill neonates. 
Instruments: A structured dichotomous questionnaire was prepared by taking into consideration of the standard format from previous studies, SES (Kuppuswamy) Socioeconomic classifications and common features from review of literature. The data collection tool or questionnaire for in depth interview consisted of two parts. First part has information related to socioeconomic, maternal, birth and delivery related factors. The second part has information of essential newborn practices followed during and after delivery and traditional cultural practices followed. The instrument was further adapted to local context and culture. The questionnaire started with closed ended questions followed by open ended questions. The questionnaire was prepared in both English and Local (Oriya) languages for convenience of the mothers. A pilot study was conducted over 20subjects from SVPPGIP and SCBMCH, Cuttack from $1^{\text {st } J u l y ~ t o ~} 30^{\text {th }}$ August, 2014 and necessary changes were made in methodology. Questionnaire was validated according to geographical, cultural and religious factors.

\section{Collection of Data}

The data was collected and recorded systemically. Interview of mothers of neonates was carried out for nearly 20 minutes to complete one subject after obtaining their informed consent. The principal investigator Dr. Dipankar Mondal, (Postgraduate student in Pediatric department) had collected all the data from the mothers of study subjects to avoid interviewer and other biases.

\section{Analysis of Data}

Data were evaluated with SPSS for Windows version 23.0 and analysed with Chi- square test and percentages. Answer to open ended questions about traditional child care practices were listed and changed into percentages. Chi-square test was used to determine the relation between obtained percentile data and independent variables.

\section{Hypothesis}

In this study hypothesis is accepted that there will be wide variety of practices among mothers on newborn care and there will be significant association between cultural practices and beliefs related to newborn care and selected demographic variables.

\section{Ethical Considerations}

Approval was obtained from the ethical committee of SCB MCH, Cuttack. An informed consent was taken from all mothers included in the study. They were assured that the obtained data would be kept confidential.

\section{Results}

In the present study, all total 170 mothers of neonates were chosen as primary respondent and the following observations were made after analysis.

Out of 170 mothers, majority (64.1\%) were in the age group of 25 years or below (Fig. 1) and 61.8\% belonged to Joint family or extended family (Fig. 2). $91.2 \%$ of mothers belonged to Hindu religion and $7.6 \%$ belonged to Muslim Community (Fig. $3)$. Majority of the mothers $(>80 \%)$ were underMatric and $<20 \%$ were above that degree. Only 8 $\%$ of mothers were graduates (Fig. 4).More than $40 \%$ (40.6\%) mothers had family income less than 9794 whereas $21.8 \%$ of mothers had family income between 19587-39173 and 17.1\% had between 9794-14689 (Fig. 5).

More than $85 \%(85.3 \%)$ of babies were less than 2 weeks of age (Fig. 6), Male Newborns (72.9\%) outnumbered the Females (Fig. 7) and most of the newborn (62.4\%) were $1^{\text {st }}$ order babies (Fig. 8).

Even though all the mothers registered, $98.8 \%$ did antenatal checkups, $98.2 \%$ mothers took iron and folic acid tablets and $96.5 \%$ mothers underwent USG during pregnancy. $91.8 \%$ mothers consumed calorie rich diet while $8.2 \%$ mothers consumed calorie restricted diet. $11.8 \%$ mothers were sent to mother's home during pregnancy (Table-01). Most of babies (92.4\%) were born out of normal delivery (Fig. 9) and most of the deliveries $(97.1 \%)$ took place in hospital whereas only one baby $(0.5 \%)$ was delivered in home and rest in nursing home (Fig. 10).

So far as wrapping of the baby is concerned, old cloth was used for wrapping of majority of babies 
(69.4\%) after birth (Table-02A). Majority of babies $(81.8 \%)$ were wrapped with clothes within 5 minutes after birth whereas 11 babies were wrapped after 30 minutes of delivery and rest of the babies baring one were wrapped within 10 to 30 minutes of birth (Table -02 B).

From bathing point of view, 95.9\%\% mothers massaged the baby with oil before bath and 92.4\% mothers bathed baby after 1 week of life. $21.2 \%$ mothers performed $21^{\text {st }}$ day celebration popularly known as "Ekushiya". 16.5\% mothers applied turmeric paste to the baby before bath. 7.6\% mothers did 40th day celebration (Table-03). As regards feeding, 54\% mothers initiated breast feeding within 1 hour, while $24.7 \%$ initiated breast feeding within 1 to 4 hours and $15.9 \%$ mothers started breastfeeding after 24 hours. $91.8 \%$ mothers gave colostrums to their babies.10.6\% mothers used home remedies for digestion, $10.6 \%$ mothers gave pre lacteal feed in and $2.9 \%$ mothers gave hot water to the babies to evacuate stool (Table-04).

Regarding Umbilical cord care practice, as high as $75.9 \%$ mothers buried the cord once it was fallen while $12.4 \%$ mothers threw the cord into pond after falling and $6.5 \%$ mothers kept it in a safe place. $38.2 \%$ mothers used rectified spirit over umbilical cord, $13.5 \%$ applied heat to make the cord dry while ashes, or soot or powder or cow dung were applied in 8 babies (Table- 05).

To prevent the babies from evil eye, applying Kajal on face and forehead, tying black thread to hand or leg, applying Tika or Tilaka on forehead, tying metal with thread and tying thread with hair or piece of wood were practiced in 98.2, 32.4, 40.6, 27.6 and $3.5 \%$ of the babies respectively (Table-06). As regards Jaundice Practice, 9.4\% mothers exposed the baby to sunlight when skin turns yellow, $7.6 \%$ mothers dressed the baby with yellow clothes, $4.7 \%$ mothers gave sugar water to the baby while $4.7 \%$ mothers gave frequent breast feeding (Table-07).

Regarding miscellaneous practices, babies are not allowed to go outside after 6 PM, baby's cloth should not be placed outside at night, wiping of tongue with cloth, to leave mother and baby together, Post Delivery 40 days stay of Mother at home, instillation of oil into ears and use of eye or ear drops were reported in 91.8, 87.6, 63.5, 48.8, 26.5, 30 and $14.1 \%$ of Newborns respectively. Among the other rare practices, not cutting nail until 40 days old, use of pacifier and placing first stool of baby under bed or carpet were found in 10, 4.1 and $1.8 \%$ of NBs respectively. $73.5 \%$ of mothers are in favour of taking bath within 7 days of delivery whereas $26.5 \%$ of mothers took bath beyond 7 days of delivery (Table-08).

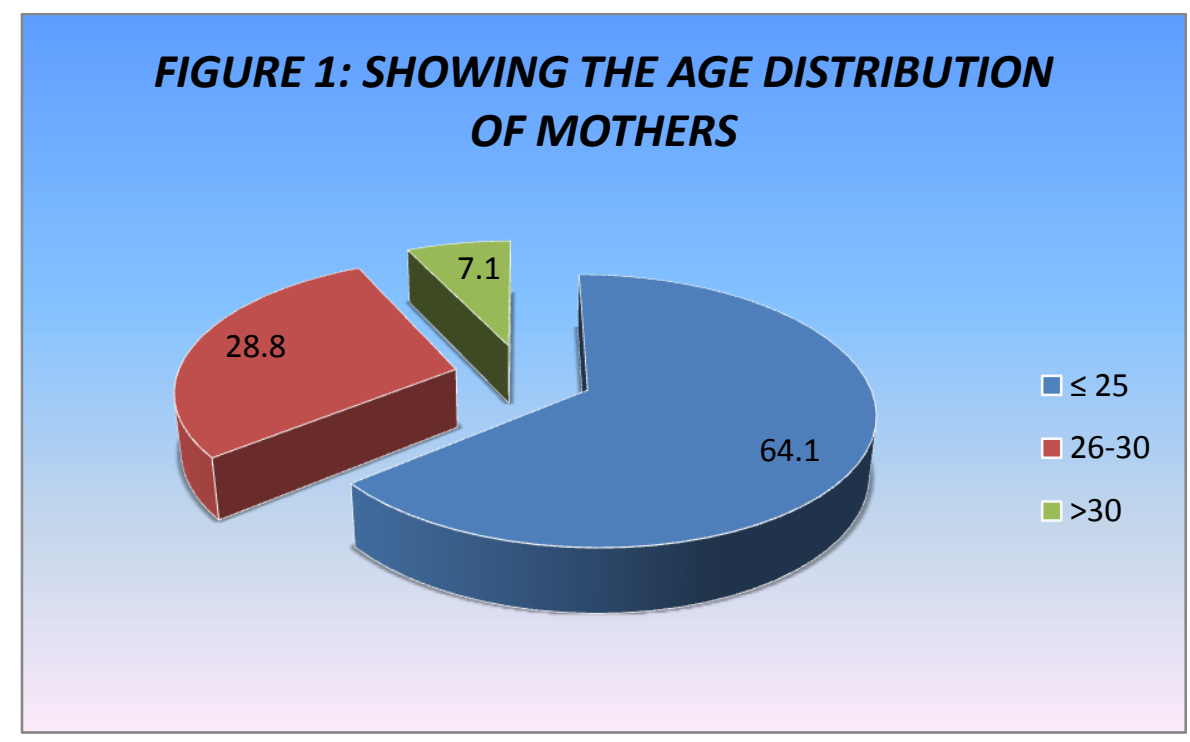


FIGURE 2: SHOWING DISTRIBUTION OF CASES ACCORDING TO TYPE OF FAMILY

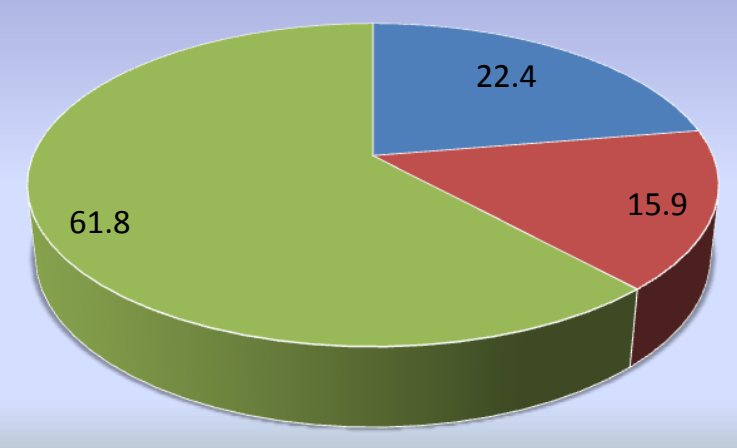

$\square$ Nuclear

$\square$ generation

$\square$ Joint or extended

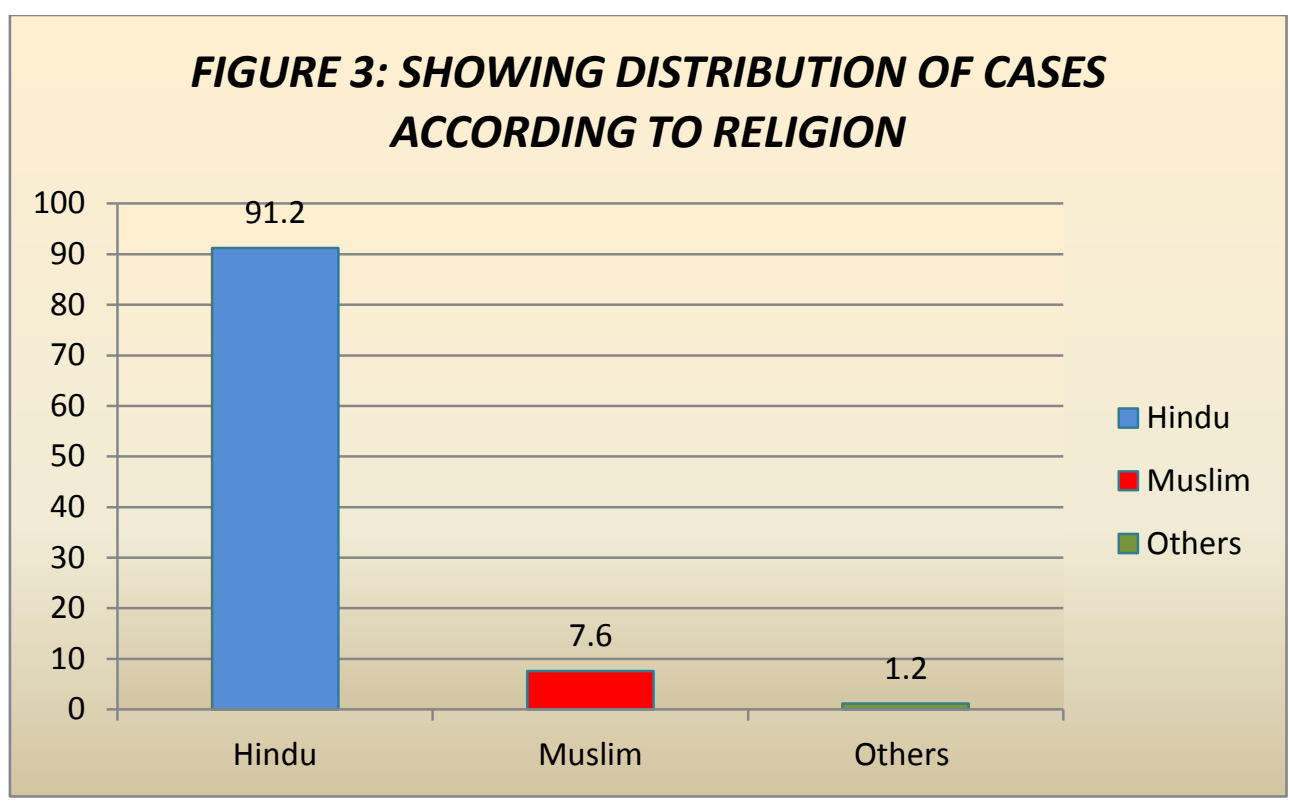

\section{FIGURE 4: SHOWING DISTRIBUTION OF CASES ACCORDING TO MOTHER'S EDUCATION}

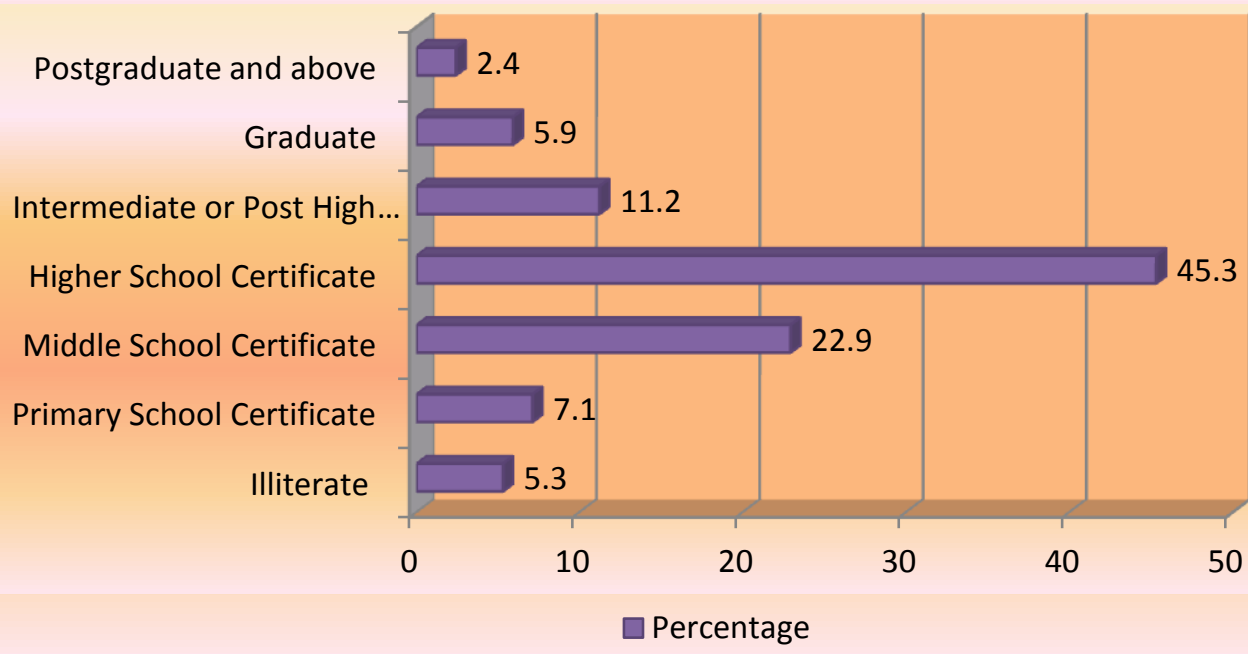



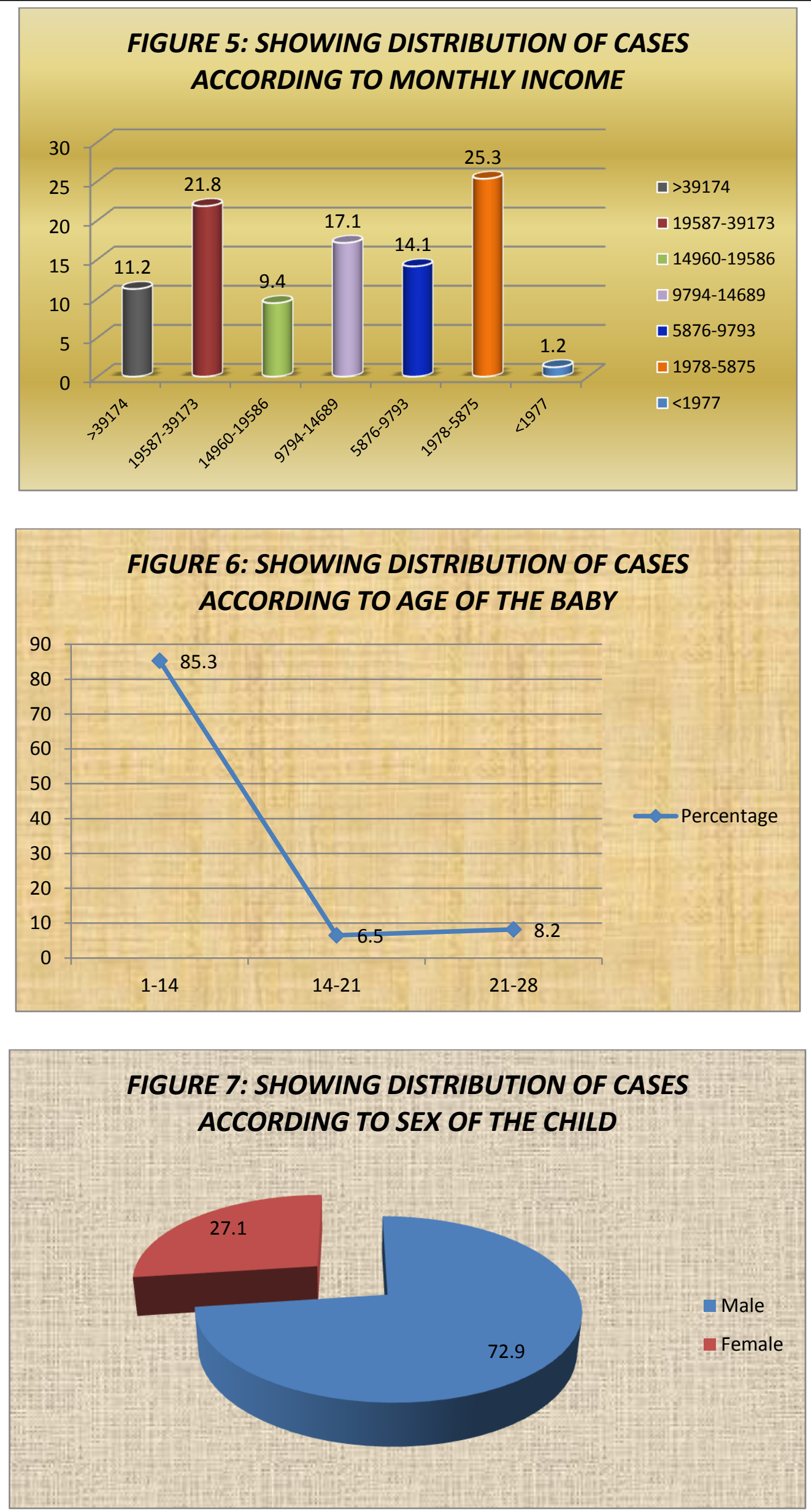


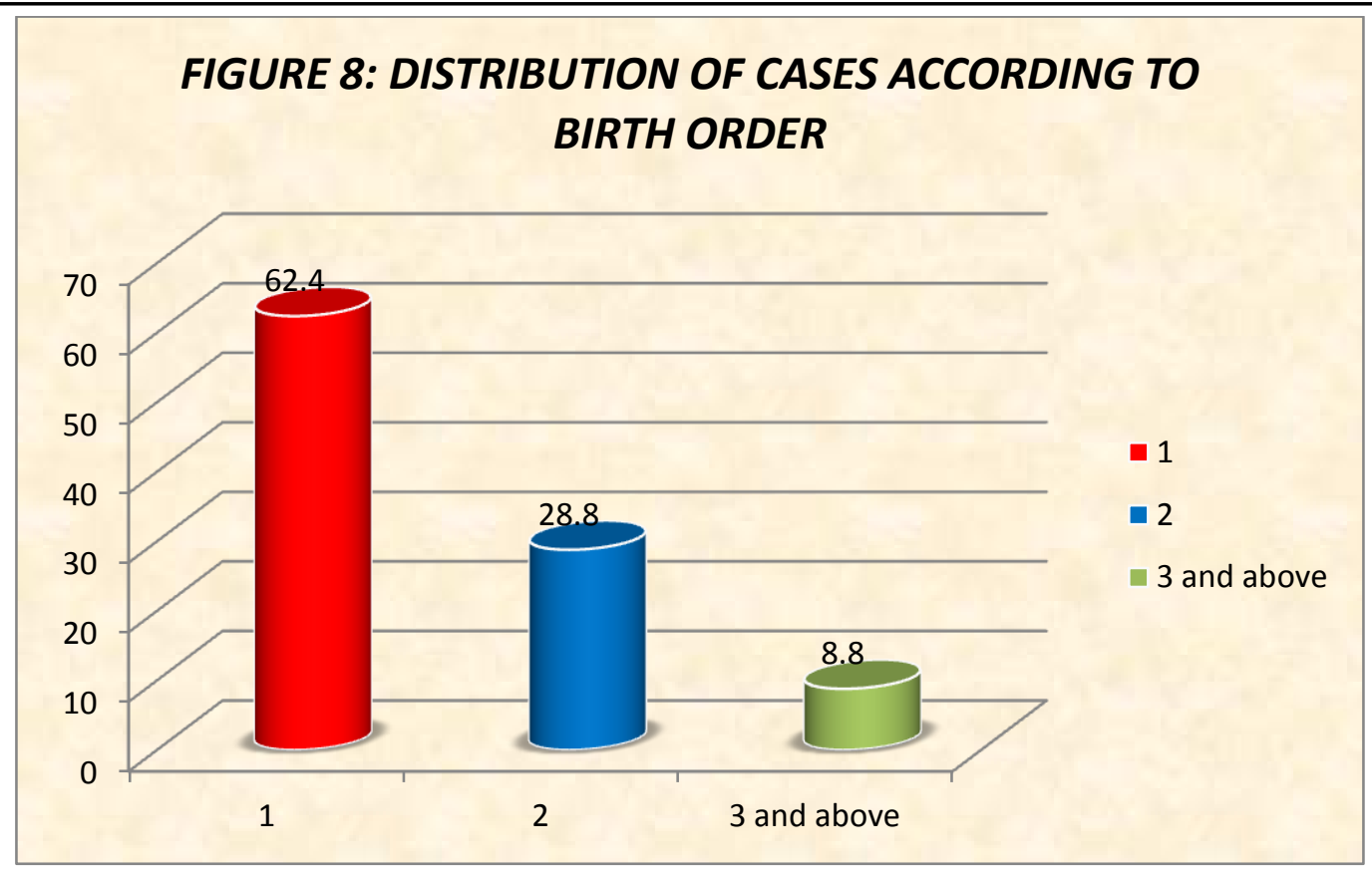

Table-01: Antenatal Care $(\mathrm{n}=170)$

\begin{tabular}{|l|c|c|}
\hline & Frequency & Percentage \\
\hline Pregnancy Registration & 170 & 100.0 \\
\hline Antenatal Checkups & 168 & 98.8 \\
\hline Iron and Folic acid taken & 167 & 98.2 \\
\hline Ultra Sonogram done & 164 & 96.5 \\
\hline Calorie Restricted diet & 14 & 8.2 \\
\hline Calorie Rich diet & 156 & 91.8 \\
\hline Stayed in mother's home & 20 & 11.8 \\
\hline
\end{tabular}

FIGURE 9: SHOWING DISTRIBUTION ACCORDING TO MODE OF DELIVERY.

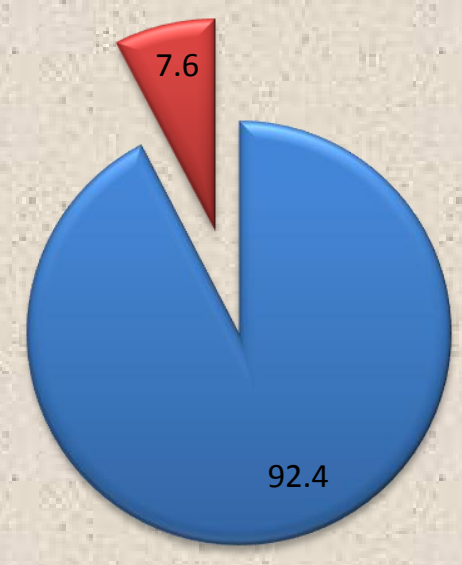

$\square$ Normal

$\square$ Caesarean section 


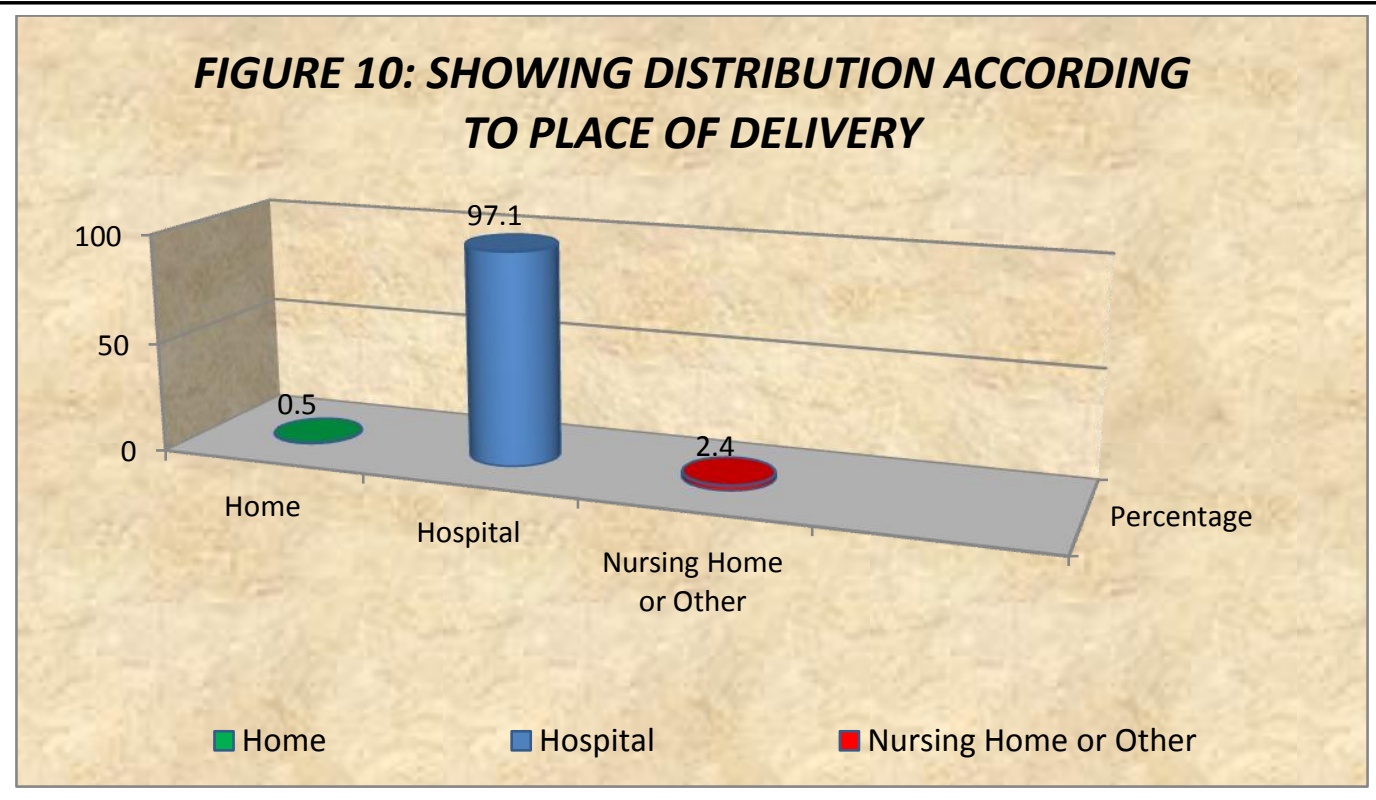

Table-02 (A): Practices related to wrapping of baby after birth

\begin{tabular}{|l|c|c|}
\hline Cloth used & Frequency & Percentage \\
\hline NEW & 52 & 30.6 \\
\hline OLD & 118 & 69.4 \\
\hline Total & 170 & 100.0 \\
\hline
\end{tabular}

Table-02 (B)

\begin{tabular}{|l|c|c|}
\hline Time of wrapping & Frequency & Percentage \\
\hline$<5$ Minutes & 139 & 81.8 \\
\hline 10-30 Minutes & 19 & 11.2 \\
\hline $30 \mathrm{Minutes}$ - 1 hour & 10 & 5.8 \\
\hline$>1 \mathrm{hr}$ & 1 & 0.6 \\
\hline unknown & 1 & 0.6 \\
\hline Total & 170 & 100.0 \\
\hline
\end{tabular}

Table- 03: Practices regarding bath $(n=170)$

\begin{tabular}{|l|c|c|}
\hline Bath Practices & Frequency & Percentage \\
\hline First bath within 7 days & 13 & 7.6 \\
\hline First bath at more than 7days & 157 & 92.4 \\
\hline 21st day celebration & 108 & 63.5 \\
\hline 40th day celebration & 13 & 7.6 \\
\hline Messaging with baby oil & 168 & 95.9 \\
\hline Applying Turmeric paste before bath & 28 & 16.5 \\
\hline Adding honey and salt to bath water & 2 & 1.2 \\
\hline Adding gold coin to bath water & 1 & 0.6 \\
\hline Adding 41 stones in bath water & 3 & 1.8 \\
\hline
\end{tabular}

Table-04: Practices regarding feeding $(\mathrm{n}=170)$

\begin{tabular}{|c|c|c|}
\hline Breast feeding initiated within & Frequency & Percentage \\
\hline$<1 \mathrm{hr}$ & 92 & 54.1 \\
\hline $1-4 \mathrm{hr}$ & 42 & 24.7 \\
\hline $4-24 \mathrm{hr}$ & 9 & 5.3 \\
\hline$>24 \mathrm{hr}$ & 27 & 15.9 \\
\hline \multicolumn{3}{|l|}{ Colostrum } \\
\hline Given & 156 & 91.8 \\
\hline Discarded & 14 & 8.2 \\
\hline Prelacteal Feed & 18 & 10.6 \\
\hline Feeding milk mixed with " kumkumkesar" & 3 & 1.8 \\
\hline Giving home remedies for digestion & 18 & 10.6 \\
\hline Giving hot water to evacuate stool & 5 & 2.9 \\
\hline
\end{tabular}


Table- 05: Practices related to cord care $(n=170)$

\begin{tabular}{|l|c|c|}
\hline & Frequency & Percentage \\
\hline Applying ashes or soot or powder or cow dung & 8 & 4.7 \\
\hline Use of rectified spirit & 65 & 38.2 \\
\hline Applying heat to make it dry & 23 & 13.5 \\
\hline When umbilical cord dries and falls: & 129 & 75.9 \\
\hline Burying & 21 & 12.4 \\
\hline Throwing into pond & 11 & 6.5 \\
\hline Keeping it safe
\end{tabular}

Table-06: Practices to prevent Evil Eye $(n=170)$

\begin{tabular}{|l|c|c|}
\hline & Frequency & Percentage \\
\hline Applying Kajal on face and forehead & 167 & 98.2 \\
\hline Tying black thread to hand or leg & 55 & 32.4 \\
\hline Applying Tika or Tilaka on forehead & 69 & 40.6 \\
\hline Tying metal with thread & 47 & 27.6 \\
\hline Tying thread with hair or piece of wood & 6 & 3.5 \\
\hline
\end{tabular}

Table-07: Practices related to care during jaundice $(n=170)$

\begin{tabular}{|l|c|c|}
\hline & Frequency & Percentage \\
\hline Exposing to sunlight & 16 & 9.4 \\
\hline Giving sugar water to baby & 8 & 4.7 \\
\hline Dressing baby with yellow clothes & 13 & 7.6 \\
\hline Giving frequent breast feeding & 8 & 4.7 \\
\hline
\end{tabular}

Table-08: Other practices $(n=170)$

\begin{tabular}{|l|c|c|}
\hline & Frequency & Percentage \\
\hline Instillation of oil into ears & 51 & 30 \\
\hline Use of eye or ear drops & 24 & 14.1 \\
\hline Use of pacifier & 7 & 4.1 \\
\hline Wiping of tongue with cloth & 108 & 63.5 \\
\hline Baby is not allowed outside after 6 PM & 156 & 91.8 \\
\hline Baby's cloth should not be placed outside at night & 149 & 87.6 \\
\hline Placing first stool of baby under bed or carpet & 3 & 1.8 \\
\hline Not cutting nail until 40 days old & 17 & 10 \\
\hline To leave mother and baby together & 83 & 48.8 \\
\hline Post Delivery 40 days stay of Mother at Home & 45 & 26.5 \\
\hline Mother should take bath after delivery: & & \\
\hline Within 7 days & 45 & 73.5 \\
\hline$>7$ days & 125 & 26.5 \\
\hline
\end{tabular}

\section{Discussion}

In the present study "Traditional cultural practices and beliefs on neonatal care among mothers" practices by mothers during pregnancy, birth and after delivery were included.

The demographic profile revealed that out of 170 mothers, majority $(61.4 \%)$ were in the age group of below 25 years (Fig.-1), most (61.8\%) of mothers belonged to Joint or Extended family (Fig.-2), 91.2\% were Hindu by religion (Fig.-3), majority belonged to under-Matric (>80\%) (Fig.4) and more than $40 \%$ (40.6\%) mothers had family income less than 9794 (Fig.-5). Reshma et al (2014) found that majority of mothers (46\%) were in the age group of 26-30 years, 57\% belonged to nuclear family, $57 \%$ were Hindu by religion, most (42\%) belonged to under Matric and $40 \%$ had family income less than $11361 .^{[6]}$ So distribution of religion, education and monthly family income in both the studies were almost similar.

$85.3 \%$ of the babies were in the age group of 1-14 days (Fig.-6), 72.9\% were males (Fig.-7), most of the newborns $(62.4 \%)$ were $1^{\text {st }}$ order babies (Fig.$8)$. Grover $\mathrm{P}$ et al (2012) found that majority (40\%) of babies were in the age group of 14-21 
days, $56 \%$ were male babies and $44 \%$ babies were $3^{\text {rd }}$ order and above. ${ }^{[7]}$ So male babies outnumbered females in both the studies.

In our study which was conducted at a tertiary care hospital, $100 \%$ mothers did pregnancy registration, $98.8 \%$ mothers did Ante-Natal checkups, 98.2\% mothers had taken 100 IFA tablets and $96.5 \%$ mothers did USG during pregnancy (Table-01). According to HMIS analysis report 2013 the percentage of pregnant women registered within 1st trimester for Odisha is $51 \%$. The percentage of women registered for Ante-Natal Care services is $84 \%$ for Odisha. The percentage of pregnant women received $3 \mathrm{ANC}$ is estimated as $74 \%$ for Odisha. The percentage of pregnant women received 100 IFA tablets for Odisha is $76 \% .{ }^{[8]}$ According to NFHS-3 report for Odisha $87.4 \%$ mothers received Ante-Natal Checkups. The percentage of mothers receiving IFA tablets is $83.1 \%$ while the percentage of pregnancy with USG was only $14.1 \% .^{[9]}$ This clearly shows pregnancy registration, antenatal care and IFA intake is much higher in this study which indicates well implementation of Reproductive and Child Health $(\mathrm{RCH})$ programme in Odisha. 8.2\% mothers consumed calorie restricted diet and $11.8 \%$ mothers were sent to mothers home during pregnancy (Table-01). No previous record is available regarding this practice.

In our study $92.4 \%$ were normal deliveries and 7.6\% were caesarean sections (Figure-9), 97.1\% deliveries took place at hospital while $0.5 \%$ deliveries took place at home (Figure-10). According to HMIS report 2013, 10\% deliveries are caesarean sections in Odisha and the percentage of institutional deliveries against total ANC registration for Odisha is $77 \% .{ }^{[8]}$ According to NFHS-3 data percentage of C-sections in Odisha is $5.1 \%$, while percentage of deliveries in health facility is $35.6 \%$ and percentage of deliveries at home in Odisha is $63.8 \% .{ }^{[9]}$ suggesting increased trends of hospital deliveries and normal deliveries preferred over caesarean section in Odisha.
Mothers included in this study performed traditional practices of first bath to the babies. 95.9\% mothers massaged with baby oil before bath (Table-03). This is almost similar to Reshma et al (2014), who found that 95\% mothers massaged with baby oil before bath ${ }^{[6]}$. $16.5 \%$ mothers applied turmeric paste to the baby before giving $1^{\text {st }}$ baby bath (Table-03). Benefits of oil massaging before bath may include improved skin condition, prevention of skin injury and skin infection, improved thermoregulation due to decreased trans epidermal water loss, absorption of essential lipids, and enhanced maternal-infant bonding with repetitive tactile stimulation ${ }^{[10]}$. In $63.5 \%$ of babies, mothers performed $21^{\text {st }}$ day celebration which is commonly performed by Hindu communities ( $\mathrm{p}$ value 0.00 ), popularly known as 'Ekushiya' (Table-03). 7.6\% mothers performed $40^{\text {th }}$ day celebration which is commonly performed by Muslim communities ( $p$ value 0.00 ). To our knowledge there have not been any study reporting about $21^{\text {st }}$ day and $40^{\text {th }}$ day celebration. Reshma et al found that $24 \%$ mothers applied turmeric paste before giving bath [6]. In our study $92.4 \%$ mothers gave first baby bath after 7 days of life (Table-03). Grover P et al (2012) found that $34 \%$ mothers gave first baby bath after 1 week of life. ${ }^{[7]}$ Mothers added honey and salt, gold coin and 41 stones to bath water in $1.2 \%, 0.6 \%$ and $1.8 \%$ respectively (Table-03). The mothers believed that their babies do not smell bad and become rich when they practice these traditions.

Breast-feeding was initiated within 1hour by $54.1 \%$ mothers whereas it took 1 to 4 hours for $24.7 \%$ of mothers and more than 24 hours for $15.9 \%$ (Table-04). Grover P et al found that only $12 \%$ mothers initiated breastfeeding within 1hour, $44 \%$ within 4 hours and $30 \%$ after 24 hours $^{[7]}$. The result of our study was comparatively higher regarding initiation of breast feeding within 1 hour. WHO recommends breastfeeding should be initiated within first hour of birth and exclusive breastfeeding up to 6 months of life. ${ }^{[1]}$ 
$8.2 \%$ mothers discarded colostrums and $10.6 \%$ used pre lacteal feeding in the form of honey, sugar water and glucose water (Table-04). Reshma et al found that $16 \%$ mothers discarded colostrums and $31 \%$ mothers gave pre lacteal feeds ${ }^{[6]}$. The reason why colostrums is not given by the mothersis that they believed colostrums is dirty and may be harmful to the baby. The reasons behind giving pre lacteal feedings is that there is a preference for giving sweets, these foods may influence the child's personality and protect from diseases. These practices are harmful and should be discouraged. Colostrums should be given as it increases immunity ${ }^{[12]} .10 .6 \%$ mothers gave home remedies for digestion, $2.9 \%$ mothers gave hot water to evacuate stool and $1.8 \%$ mothers fed milk mixed with 'kumkumkesar' (Table-04). Reshma et al found that $53 \%$ mothers gave home remedies for digestion in the form of Gripe mixture, garlic, ginger and herbal leaves and 32\% mothers gave hot water to evacuate stool and $16 \%$ mothers fed milk mixed with 'kumkumkesar' ${ }^{[6]}$. So traditional practices related to feeding was comparatively low in our study. Use of home remedies for digestion should be discouraged.

Application of heat to the umbilical cord was found in $13.5 \%$ babies, use of rectified spirit was found in $38.2 \%$ babies, $75.9 \%$ mothers buried umbilical cord after falling while $12.4 \%$ mothers threw the cord into pond after falling and 6.5\% mothers kept it in a safe place (Table-05). Reshma et al found that 55\% mothers applied ashes, soot, powder or dry cow dung on the umbilical cord, $10 \%$ mothers applied heat to the cord and $24 \%$ mothers buried the cord after falling. No comparative data is available regarding application of rectified spirit over cord. It is believed that personality of baby is influenced by the place where cord is buried. They buried the cord at school so that babies can have good education. They also buried near temple or mosque so that their babies would become devotee to god. Application on cord is a risk factor for sepsis, should be discouraged. Rest of the practices related to cord have no negative effect.
Application of Kajal on baby's face as found in $98.2 \%$ of cases in our study (Table-06) is relatively higher than in other studies made by Reshma et al $(82 \%)$ and Grover P et al $(76 \%)^{[6,7]}$. In our study $32.4 \%$ mothers tied black thread to the hands or legs, $40.6 \%$ applied 'Tika' or 'Tilaka' on forehead, $27.6 \%$ tied metals with thread and $3.5 \%$ tied hair with thread (Table-06). Reshma et al found that $66 \%$ mothers tied black thread to prevent bad eye ${ }^{[6]}$. Believing in evil eye is observed in every society. However these practices should be discouraged as these increase risk of neonatal sepsis.

During jaundice, $9.4 \%$ mothers exposed baby to sunlight, $7.6 \%$ mothers dressed the baby with yellow cloth and $4.7 \%$ mothers gave sugar water to the baby and $4.7 \%$ mothers gave frequent breastfeeding (Table-07). Reshma et al found that $73 \%$ mothers exposed to sunlight, $6 \%$ mothers dressed baby with yellow clothes and $11 \%$ mothers gave sugar water to the baby during jaundice. So exposing to sunlight during jaundice is very less in our study. Frequent breastfeeding which is beneficial during neonatal jaundice is quite less in our study so mothers should be encouraged to continue breast feeding during jaundice.

91.8\% mothers believed that baby should not be taken outside after evening, $87.6 \%$ mothers believed that baby's clothes should not be placed outside at night, $63.5 \%$ mothers wiped tongue of baby with cloth, $1.8 \%$ mothers placed $1^{\text {st }}$ stool of baby under carpet, $10 \%$ mothers believed that $1^{\text {st }}$ nail cut should be done at 40 days of age (Table08) and all these practices are well comparable with study done by Reshma et $\mathrm{al}^{[6]}$.

$26.5 \%$ mothers took bath after7 days of delivery. No previous data is available regarding this practice. This practice may contribute to neonatal sepsis, so mothers should be advised to take regular bath after delivery.48.8\% mothers believed mother and baby should be left together alone in a single room. This is a good practice as it promotes bonding between baby and mothers and 
prevents neonatal sepsis. No previous data is available regarding this practice.

Conclusion:- In this $21^{\text {st }}$ century, while Medical Science has evolved in so many aspects along with development of a good number of effective health programmes by the Government, traditional cultural child care practices are not that much uncommon in this part of Odisha just like prevailing in other corners of the country. Some of the practices performed by the mothers are very good and must be encouraged, some are very much harmful and need to be discouraged while some are harmless having no negative effect on the babies which should be simply ignored.

In order to change traditional child care practices with harmful effects on mother and baby's health, first these practices should be identified followed by revealing of the underlying causes and beliefs responsible for these practices. Cultural practices and beliefs should be taken into account and consideration while planning for different National Health Programmes exclusively targeted at and promoted towards the improvement of the health status of Mothers and Babies.

\section{Limitations}

- As this study, population belongs to the only babies needing hospitalization, the number of babies and mothers represent only the tip of the iceberg, thus prevalence of traditional cultural practices cannot be taken as the true figure considering the society in general.

- This study comprises only small number of neonates and mothers suggesting very small sample size.

- Community Survey could have been conducted to cover a sizeable population and maintaining uniformity of the study.

- Hence, study involving large number of cases at community level is needed to reaffirm the substantial results.

\section{Bibliography}

1. Swain D.Cultural beliefs and practices in pregnancy and child birth in India. Journal of Nightingale Nursing Times June 2010; Vol 6(3):29-32.

2. Madhu K, Chowdary S, Ramesh M. Breastfeeding practices and newborn care in rural areas. Indian $\mathbf{J}$ community med. 2009 July; 34(3): 243-46.

3. Darmstadt GL, Bhutta ZA, Cousens $\mathrm{S}$, Adam $\mathrm{T}$, Walker $\mathrm{N}$ et al; Evidencebased, cost-effective interventions: how many newborn babies can we save?; Lancet. 2005; 365(9463):977-88.

4. Lawn JE, Cousens S, Bhutta ZA Darmstadt GL, Martines J et al; Why are 4 million newborn babies dying each year?; Lancet. 2004; 364(9432):399-401.

5. Reshma, Sujatha R: Cultural practices and beliefs on newborn care among mothers in a selected hospital of Mangalore Taluk. NUJHS. June 2014; 4(2):21-24.

6. Reshma, Sujatha R: Cultural practices and beliefs on newborn care among mothers in a selected hospital of Mangalore Taluk. NUJHS. June 2014; 4(2):21-24.

7. Grover P, Chhabra P. Neonatal care practices in urban villages. Indian Medical Gazette. Jan 2012; 32-38.

8. Odisha HMIS analysis report 2013. Available from www.nrhmorissa.gov.in/writereaddata/Upl oad/Documents/District\%20Ranking.pdf.

9. NFHS-3 Orisha state report. Available from

http://rchiips.org/nfhs/orissa_report.shtml

10. Luke CM, Gary LD, SubarnaKK,James MT. Traditional Massage of Newborns in Nepal: Implications for Trials of Improved Practice. J Trop Pediatr. 2005 Apr; 51(2): 82-86.

11. Breastfeeding recommendations of WHO. Available at http://www.who.int/topics/breastfeeding/e $\mathrm{n}$ 
12. Hanson LA: Immunobiology of Human Milk: How Breastfeeding Protects Babies.

Amarillo, TX, USA: Pharmasoft

Publishing, 2004. 